\title{
Detection of viral genomes from endomyocardial biopsy samples in dilated cardiomyopathy in hungary
}

\author{
Hőgye $M^{1}$, Csanády $M^{1}$, Deák $J^{2}$, Terhes $G^{2}$, Kelle $B^{2}$, Sepp $R^{1}$, Iványi $B^{3}$ and Forster $T^{1}$ \\ ${ }^{1}$ Department of Internal Medicine and Cardiology Centre, Hungary \\ ${ }^{2}$ Department of Clinical Microbiological Diagnostics, Hungary \\ ${ }^{3}$ Department of Pathology, University of Szeged, Szeged, Hungary
}

\begin{abstract}
Background: It is well known that viral myocardites may play a significant role as aetiological factors in the development of dilated cardiomyopathy (DCM). The precise virological diagnosis is very important as it can have therapeutic consequences. The viral incidence reported by the various authors differs in the different geographical regions; we therefore set out to survey the incidence of viruses in a Hungarian DCM population.
\end{abstract}

Method: Our cardiology unit we diagnos and treat considerable numbers of DCM patients. During the period 2004-2012, qualitative and quantitative reverse transcriptase PCR methods were applied to detect the virus particles in endomyocardial biopsy samples from 93 cases.

The 93 cases included 88 DCM patients were in severe functional stages (NYHA III-IV) with a significantly reduced systolic function of the left ventricle (mean ejection fraction of 20-25\%). Their average age was 40.0 years, and the male:female ratio was 52:36. The viruses examined: parvovirus B19, adenovirus, enterovirus, cytomegalovirus, the Epstein-Barr virus, herpes simplex virus-1, herpes simplex virus-2, and human herpes virus-6.

Result: 449 PCR examinations were performed. Viral genomes were found in 26 cases: parvovirus B19 in 12 cases, cytomegalovirus, enterovirus, the Epstein-Barr virus and herpes simplex in 3 cases each, and adenovirus and human herpes virus- 6 in 1 case each.

Conclusion: The incidence of parvovirus B19 proved highest, but cytomegalovirus, enterovirus, the Epstein-Barr virus and herpes simplex virus were also relevant. Our finding of 33\% virus positivity in DCM is similar to data published on other European cohorts.

\section{Introduction}

The earlier viral myocardites can account for a considerable proportion of the aetiological factors of dilated cardiomyopathies (DCMs) [1]. The 'primary' DCMs in fact comprise three large subgroups: the familial/genetic subgroup (30\%), those of toxic origin and the viral/immune cardiomyopathy subgroup (15\%).

It has long been known that many viruses (either RNA or DNA viruses) may cause myocarditis. It is a comparatively new observation that the myocardites in DCMs are caused relatively frequently by certain viruses, but appreciably more rarely by others. Following the availability of viral genome detection through virological examinations of myocardial biopsy samples, it has emerged that, of the enteroviruses, Coxsackie B3, human herpes virus 6 (HHV6) and certain adenovirus types are found most often [2-6]; these may be referred to as 'cardiotropic' viruses. In contrast, viral myocarditis is caused more rarely by the Epstein-Barr virus (EBV), cytomegalovirus (CMV) and hepatitis $\mathrm{C}$ virus.

The aetiological role of parvovirus B19 in the case of viral myocardites (first suggested by Kandolf [3]) was initially discounted by many authors, but has now become an accepted fact.

The RNA viruses include the enteroviruses (Coxsackie A and B3, ECHO viruses), mumps virus, and influenza $\mathrm{A}$ and $\mathrm{B}$ viruses, while the DNA viruses include the adenoviruses, parvovirus B19, herpes simplex virus (HSV)-1 and 2, HHV6, varicella zoster virus and the EBV.
The outcome of viral myocarditis is extremely variable: in some cases there may be a spontaneous recovery after a certain time, whereas in others there may be a fulminant course, leading to sudden death. In a considerable proportion of the cases (15-20\% or even $30 \%$ according to the most recent publications $[4,8])$, DCM develops.

Viral persistence in the myocardium can be demonstrated only by means of histological and virological examinations of myocardial biopsy samples.

Other techniques (e.g. cardiac MRI) can be extremely useful detection of myocarditis, but the virus-persistence in the myocites can only be detected by means of PCR examinations of endomyocardial biopsy-patterns.

\section{Method}

We have been carrying out the diagnostic examinations and treatment of DCM patients for many years. Since we have the possibility to perform diagnostic histological and virological examinations, from among the patients in the period 2004-2012 we randomly selected 93

*Correspondence to: Márta Hőgye, Szeged, Semmelweis, Hungary, Tel: +36-62545220; E-mail: csanady.miklos.1@med.u-szeged.hu

Key words: dilated cardiomyopathy, viral myocarditis, viral genomes

Received: February 22, 2018; Accepted: March 18, 2018; Published: March 21 , 2018 
cases with the aim of determining the frequencies of virus particles (viral DNA and RNA) in myocardial biopsy samples. Qualitative, quantitative and quantitative reverse transcriptase PCR methods were applied, depending on whether we were looking for a DNA or an RNA virus. The virological diagnosis is important as it may have therapeutic consequences. Additionally, it is of interest to compare the natures of the viruses causing the myocarditis and the incidences of the various types in Hungary with the published international data.

The patients were predominantly admitted from the south-east of Hungary, but small numbers came from many other parts of the country.

Endomyocardial biopsies were performed on the 93 patients, and histological and virological examinations were carried out on the myocardial samples. Before the endomyocardial biopsies informed consent was obtained from each patients. In 5 of the cases, the histological examination revealed restrictive cardiomyopathy (RCM); the other 88 cases were demonstrated to involve DCM. Among the range of cardiological examination procedures on these 88 clinically severe DCM cases (NYHA stages III-IV), who exhibited a decreased left ventricular function (left ventricular ejection fraction measured by echocardiography: 20-25\%), endomyocardial biopsies were performed $[7,8]$. The diagnosis in the $5 \mathrm{RCM}$ cases was already clear from the previous echocardiography, but myocardial biopsies were performed in these cases too, primarily for histological and not virological purposes. However, virological examinations were also carried out on these samples, and confirmed the absence of viruses in 4 of these 5 nonDCM cases (1 patient was CMV-positive), who subsequently served as 'control' cases, ethical considerations ruling out the possibility of the use of true controls. Naturally, these 5 RCM patients were excluded from the processing of the present data.

The targeted virus detection was therefore carried out on the myocardial biopsy samples from the $88 \mathrm{DCM}$ patients. These patients had an average age of 40.0 years, and the male:female ratio was 52:36
(1.44:1). They were predominantly admitted from south-east Hungary, but small numbers came from many other regions of the country (Figure 1).

Virological examinations: The endomyocardial biopsy samples (1-3 per patient; a total of 449 PCR examinations) were taken from the right ventricle, and mainly from the right ventricular septum, by recommended methodology $[7,8]$. The samples were subjected to virological processing (nucleic acid isolation) by the Qiagen method without delay (on the same day as sample-taking). Qualitative and quantitative PCR was utilized for detection of the viral genomes [9]. Initially only qualitative PCR was performed in every case, but later quantitative real-time (RT) PCR was carried out too. The viruses tested in the myocardium: parvovirus B19, adenovirus, enterovirus, CMV, HSV1, HSV2 and HHV6.

\section{Result}

Viral genomes were found in the myocardial samples in 26 cases during the virological examinations of the samples from the $88 \mathrm{DCM}$ patients. Parvovirus B19 occurred in 12 cases, CMV, the EBV, HSV and enterovirus in 3 cases each, and adenovirus and HHV6 in 1 case each (Figure 2). Thus, parvovirus B19 was seen most frequently, though $\mathrm{CMV}$, the EBV, HSV and enteroviruses were also significant (Figure 3). No complications were observed in the course of the myocardial biopsies.

\section{Discussion}

Depending on their functional stage, DCMs should be treated in accordance with the international guidelines relating to the well-known 'basic therapy' in cases of chronic heart failure. Besides rest, appropriate loading of the condition and changes in lifestyle, the therapeutic possibilities include blockade of the neurohumoral over- activity, i.e. the administration of ACE inhibitors or angiotensin-II receptor blockers, ß-blockers (metoprolol, bisoprolol, carvedilol or nebivolol) and a low-dose aldosterone antagonist (25-50 $\mathrm{mg}$ spironolacton). Additionally, digoxin (with close control of the serum level) and

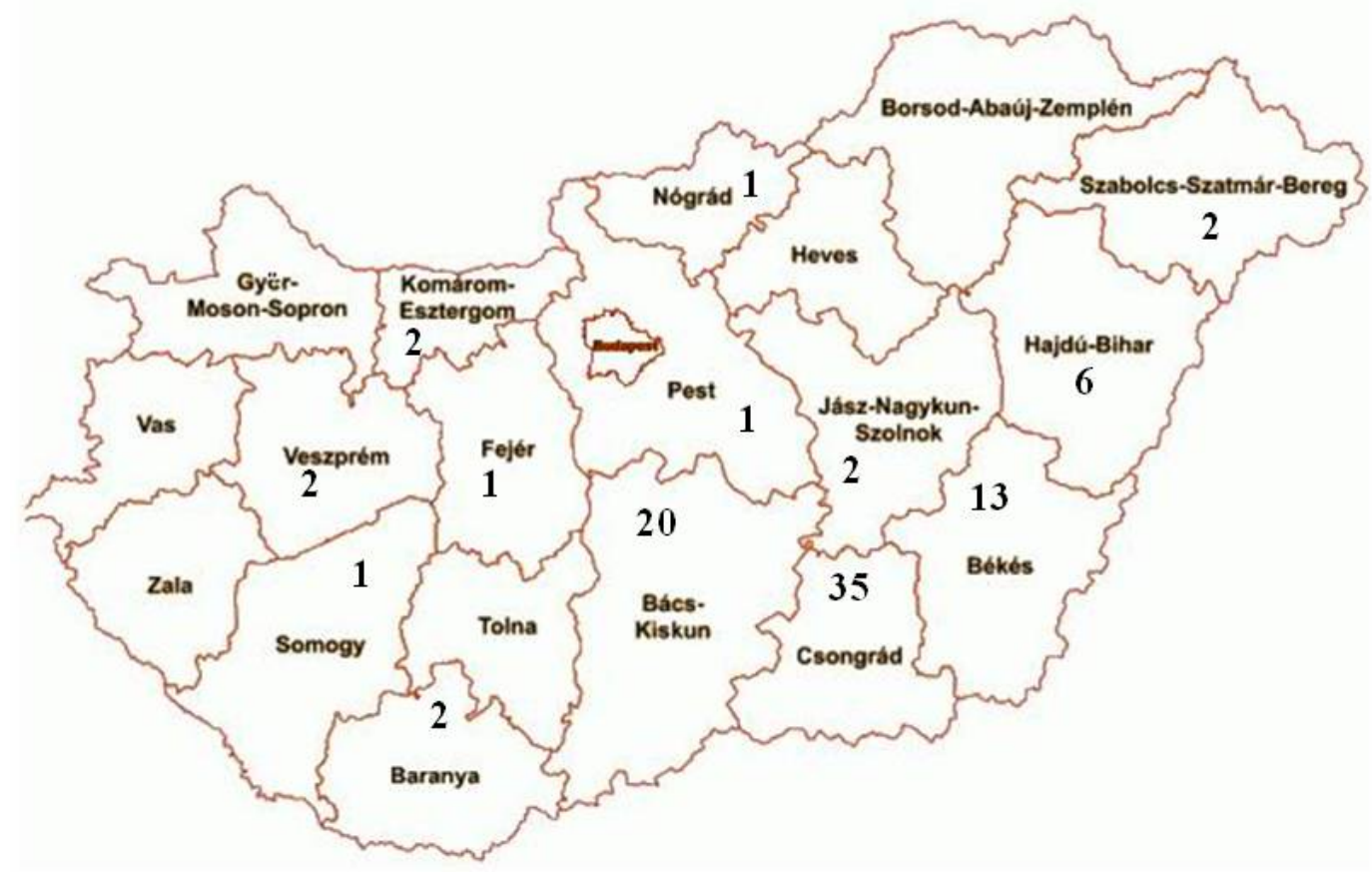

Figure 1. A map of counties of Hungary, demonstrating the areas from which the DCM patients were referred 


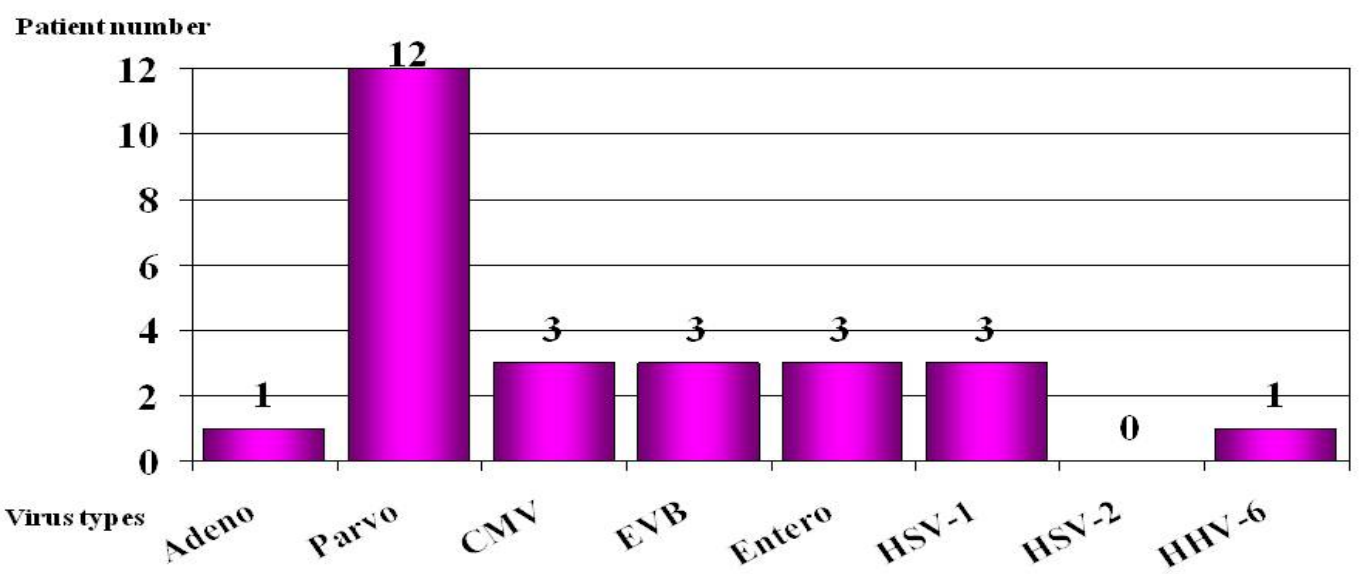

Figure 2. Distribution of the viral genomes found in the myocardial samples in the 26 virus-positive cases

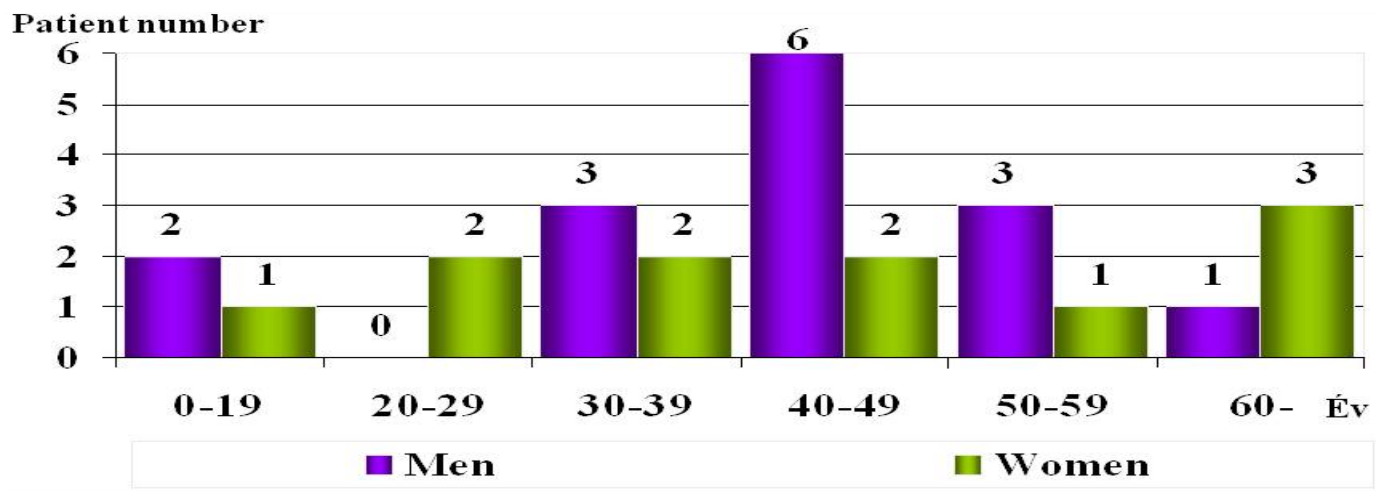

Figure 3. Distributions of the virus-positive cases by age and sex

diuretics in large doses and in combinations may be administered as parts of the pharmacological therapy. Non-pharmacological therapy, including resynchronizational, biventricular pacemaker treatment ICD implantation or even supporting devices of left ventricle function should also come into consideration. Other vasodilatators (in severe cases), supplementary anticoagulant therapy and (particularly in atrial fibrillation) antiarrhythmic treatment with amiodarone may also be given. As an ultimate refuge, heart transplantation may be considered in certain severe cases $[10,11]$. The patients are primarily referred to cardiological centres for the performance of special diagnostic methods (invasive examinations, endomyocardial biopsy, and histological and virological examinations) with the aim of the appropriate pharmacological and non-pharmacological therapy. It is particularly important to identify possible myocardites among those young DCM patients in a severe condition, with a very poor left ventricular function and symptoms of heart failure, whose state is progressing inspite of the above traditional therapy. The aim of the virological diagnosis is the recognition of viral myocardites with demonstration of the type and persistence of the virus in the myocardium, and if possible the performance of antiviral or other treatment in the given case.

The presence or absence of virus particles in tissue samples obtained via myocardial biopsies is an essential question. In the event of the presence of viral genomes, virus eradication treatment must be considered; while in the absence of viruses (and only then), immunosuppressive therapy may be performed in accordance with the indications. We carried out the virological examinations of our DCM patients with such purposes. Viral genome examinations on such a large number or patients have not been performed in Hungary previously. Mantke et al. [12] found parvovirus positivity in explanted hearts in $7 \%$ of their cases. Our own virological examinations are somewhat of an 'eclectic' nature as the tests were not started simultaneously on all the viruses; for example, tests for adenovirus and HHV6 were not performed initially. This part of our viral examinations have some retrospective character.

Anyhow approximately one-third of our DCM patients proved to be virus-positive. Similarly as reported by other authors [13].

The use of viral eradication in the treatment has been investigated by German authors over periods of years, and the value of the administration of interferon- $\beta$ (Beneferon) has been clearly demonstrated [14]. In every treated case, significant improvements were achieved in the left ventricular function and the NYHA stage. Interferon- $\beta$ proved most effective in those viral myocarditis patients where the pathogen was adenovirus or enterovirus $[14,15]$. The patients tolerated the treatment well, and interruption of the administration was not necessary in any of the cases. Even a single treatment was sufficient for viral eradication [15]. This was confirmed by other authors [15], who also concluded that the effect of interferon was only moderate, and not sufficiently convincing, in the event of parvovirus B19 positivity.

Maisch et al. [16] reported that parvovirus B19 and adenovirus may be eradicated with pentaglobin. Following pentaglobin treatment, the inflammatory phenomena were reduced by $70 \%$, and the control 
biopsies indicated that eradication was successful in $40 \%$ of the cases. Staudt et al. [17] found that there is a possibility for elimination of the cardiotoxic antibodies (antiactin, antimyosin, anti-beta-1 receptor, etc. antibodies) with the aid of apheresis (plasma immunoadsorption). However, this does not comprise part of the routine treatment. Mention must definitely be made of the possibility of immunosuppressive treatment, against which there is no appreciable obstacle in Hungarian practice, though it can be effective only if the examinations on the biopsy sample confirm the presence of an immune process, and the virological examinations reveal that the myocardium is free of viral genome. Frustaci et al. [18] unambiguously demonstrated that the cases that responded well to immunosuppression were viral genomenegative. The patients who did not respond to the treatment were all virus-positive.

Even today, immunosuppressive therapy may form part of the treatment in acute, very severe, fulminant, life-threatening cases, regardless of the knowledge of the viral genomes, but it is not recommended in the long term. Naturally, however, the utilization of immunosuppressive treatment continues to be justified in cases involving the various already known indications such as eosinophil, granulomatous, giant cell and lymphocytic myocardites and confirmed autoimmune processes.

We ourselves applied immunosuppressive therapy in the treatment of DCM patients several decades ago; although this led to a temporary improvement, it was not effective in the long term, with the exception of a few cases [19]. At that time we did not have the possibility to carry out viral genome examinations, which probably explains the failure to attain a good long-term effect as it is likely that there were virus-positive cases among those we then treated. The importance of the virological diagnosis is highlighted by the fact that the subsequent therapy may depend on it [20-22]. A further reason why an effort should be made to reach an accurate aetiological diagnosis is the situation that the costs of the antiviral therapy applied in viral myocarditis are not negligible and, until the value of this therapy has been clearly proved by studies of large numbers of such patients, the lack of official financial support hampers its use in the everyday therapeutic practice. The place of these viral examinations in the diagnoses of viral myocardites and in the application of the therapeutic possibilities is illustrated by the algorithm presented in Figure 4.

\section{Conclusion}

Efforts should be made, if possible, to demonstrate virus persistence in myocardial biopsy samples from DCM patients. Parvovirus B19 proved to occur most frequently in our DCM patients, but appreciable numbers of CMV, EBV, enteroviruses and HSV were also encountered. Similarly as reported by other authors, around a third of our DCM cases (33\%) proved to be virus-positive. The identification of viruses in the myocardium is of decisive importance. The possibility of the diagnosis of viral myocarditis will hopefully become accessible more widely, for this determines the nature of the subsequent therapy.

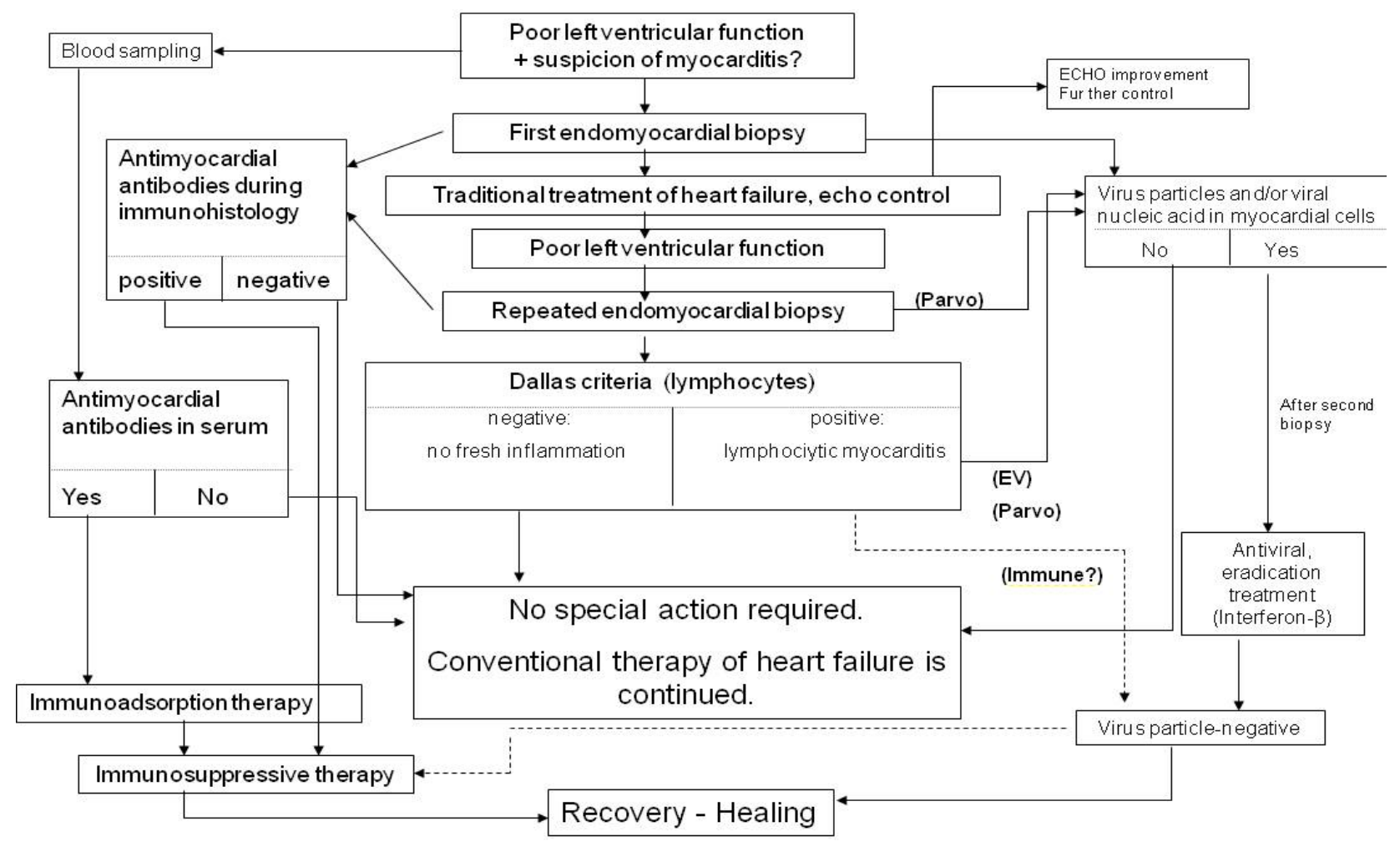

Figure 4. Algorithm of diagnoses and treatment of myocardites 


\section{References}

1. Richardson P, McKenna W, Bristow M, Maisch B, Mautner B, et al. (1996) Report of the 1995 World Health Organization/International Society and Fedration of Cardiology Task Force on the Definition and Classification of Cardiomyopathies. Circulation 93: 841-842. [Crossref]

2. Bültmann BD, Klingel K, Sotlar K, Bock CT, Baba HA, et al. (2003) Fatal parvovirus B19 associated myocarditis clinically mimicking ischemic heart disease: an endothelial cell-mediated disease. Hum Pathol 34: 92-95. [Crossref]

3. Kandolf R (2004) Virus etiology of inflammatory cardiomyopathy. Dtsch Med Wochenschr 129: 2187-2192. [Crossref]

4. Kühl U, Pauschinger M, Seeberg B, Lassner D, Noutsias M, et al. (2005) Viral persistence in the myocardium is associated with progressive cardiac dysfunction. Circulation 112: 1965-1970. [Crossref]

5. Pankuweit S, Moll R, Baandrup U, Portig I, Hufnagel G, et al. (2003) Prevalence of the parvovírus B19 genome in endomyocardial biopsy specimens. Hum Pathol 34: 497503. [Crossref]

6. Andréoletti L, Ventéo L, Douche-Aourik F, Canas F, Lorin de la Grandmaison G, et al. (2007) Active Coxsackie viral B infection is associated with disruption of dystrophin in endocardial tissue of patients who died suddenly of acute myocardial infarction. $\mathrm{J} \mathrm{Am}$ Coll Cardiol 23:50: 2207-2214. [Crossref]

7. Cooper LT, Baughman KL, Feldman AM, Frustaci A, Jessup M, et al. (2007) The role of endomyocardial biopsy in the management of cardiovascular disease: a scientific statement from the American Heart Association, the American College of Cardiology, and the European Society of Cardiology Endorsed by the Heart Failure Society of America and the Heart Failure Association of the European Society of Cardiology. Eur Heart J 28: 3076-3093. [Crossref]

8. Caforio AL, Pankuweit S, Arbustini E, Basso C, Gimeno-Blanes J, et al. (2013) Current state of knowledge on aetiology, diagnosis, management,and therapy of myocarditis: a position statement of the European Society of Cardiology Working Group on Myocardial and Pericardial Diseases. Eur Heart J 33: 2636-2648. [Crossref]

9. Schenk T, Enders M, Pollak S, Hahn R, Huzly D (2009) High Prevalence of Human Parvovírus B19 DNA in Myocardial Autopsy Samples from Subjects without Myocarditis or Dilative Cardiomyopathy. J Clin Microbiol 47: 106-110.

10. ACC/AHA (2001) Guideline for the Evaluation and Management of Chronic Heart Failure in the Adults-A Report of the American College of Cardiology/American Heart Association Task Force on Practice Guidelines. J Am Coll Cardiol 38:13.
11. ESC Guidelines for the diagnosis and treatment of acute and chronic heart failure (2012) The Task Force for the Diagnosis and Treatment of Acute and Chronic Heart Failure 2012. of the European Society of Cardiology. Developed in collaboration with the Heart Failure Association (HFA) of the ESC. Eur Heart J 33: 1787-1847.

12. Mantke O, Sitsche A, Meyer R, Klingel K, Niedrig M (2004) Analysing myocardial tissue from explanted hearts of heart transplant recipients and multi-organ donors for the presence of parvovirus B19 DNA. J Clin Virol 31: 32-39. [Crossref]

13. Maisch B, Pankuweit S (2013) Standard and etiology-directed evidence-based therapies in myocarditis: state of the art and future perspectives. Heart Fail Rev 18 761-795. [Crossref]

14. Kühl U, Pauschinger M, Schwimmbeck PL, Seeberg B, Lober C, et al. (2003) Interferon treatment eliminates cardiotropic víruses and improves ventricular function in patients with myocardial persistence of viral genomes and left ventricular dysfunction. Circulation 107: 2793-2798. [Crossref]

15. Schultheiss HP, Piper C, Sowade K, Karason JF (2008) The effect of subcutaneous treatment with interferon-beta $1 \mathrm{~b}$ over 24 weeks on safety, vírus elimination and clinical outcome in patients with chronic viral cardiomyopathy. Circulation 118: 2312

16. Maisch B, Haake S, Schlotmann (2008) Intermediate dose of pentaglobine eradicates inflammation in parvovírus B19 and adenovírus positive myocarditis. Eur Heart J 29: 2737.

17. Staudt A, Staudt Y, Dörr M, Böhm M, Knebel F, et al. (2004) Potential role of humora immunity in cardiac dysfunction of patients suffering from dilated cardiomyopathy. $\mathrm{Am}$ J Coll Card 44: 829-836. [Crossref]

18. Frustaci A, Chimenti C, Calabrese, Pieroni M, Thiene G, F et al. (2003) Immunosuppressive therapy for active lymphocytic myocarditis: virologic and immunologic profile of responders versus nonresponders. Circulation 107: 857-863. [Crossref]

19. Hogye M, Móczó I, Édes I (1978) Szivizom biopsiával igazolt autoimmun myocarditisek immunszuppressziv kezelésében szerzett tapasztalataink. Orv Hetil 128: 451-457.

20. Frustaci A, Russo MA, Chimenti C (2009) Randomized study on the efficacy of immunosuppressive therapy in patients with vírus-negative inflammatory cardiomyopathy: TIMIC study. Eur Heart J 30: 1995-2002. [Crossref]

21. Schultheiss HP, Kühl U, Cooper LT (2011) The management of myocarditis. Eur Heart $J$ 32: 2616-2625. [Crossref]

22. Guglin M, Nallamshetty L (2012) Myocarditis: Diagnosis and Treatment. Current Treatment Options in Cardiovascular Medicine 14: 637-651.

Copyright: $\odot 2018$ Hőgye M. This is an open-access article distributed under the terms of the Creative Commons Attribution License, which permits unrestricted use, distribution, and reproduction in any medium, provided the original author and source are credited. 